\title{
INCREASING INCIDENCE OF TICK-BORNE ENCEPHALITIS AND ITS IMPORTANCE IN THE SLOVAK REPUBLIC
}

\author{
Erik Dorko ${ }^{1}$, Kvetoslava Rimárová1, Peter Kizek², Milan Stebnický1, L'ubica Zákutná1 \\ 'Department of Public Health, Faculty of Medicine, University of P. J. Šafárik, Košice, Slovak Republic \\ ${ }^{21}$ st Department of Stomatology, Faculty of Medicine, University of P. J. Šafárik, Košice, Slovak Republic
}

\section{SUMMARY}

Tick-borne encephalitis (TBE) is caused by tick-borne encephalitis virus (TBEV), a virus species of the genus Flavivirus within the Flaviviridae family. In Western Europe, TBEV is transmitted primarily by the Ixodes ricinus (I. ricinus) tick. During the last 30 years, there has been a continued increase in human cases of TBE in Europe. A total number of 102 cases in Slovakia was reported in $2012(1.89 / 100,000)$, with two local outbreaks after the ingestion of raw milk and dairy products. Active vaccination is the most effective method of preventing TBE. According to the available data in Slovakia from 2012, 8,491 children under 15 years of age were vaccinated that year, which, when compared to 2009 with approximately 17,000 vaccinated children, represents a decrease of more than $50 \%$. The data on vaccination of adults are not available, but the estimated vaccination coverage in Slovakia is around 1\% $(1.3 / 100,000)$. The education of the population is also an important precautionary measure in the prevention of tick-borne illnesses.

Key words: tick-borne encephalitis, Ixodes ricinus, occurrence, prevention

Address for correspondence: E. Dorko, Department of Public Health, Faculty of Medicine, P. J. Šafárik University, Šrobárova 2, 04180 Košice, Slovak Republic. E-mail: erik.dorko@upjs.sk

\section{INTRODUCTION}

Tick-borne encephalitis (TBE), a potentially fatal neurological infection affecting humans in Europe and Asia, is caused by tick-borne encephalitis virus (TBEV) $(1,2)$.

Generally, the prevalence of zoonotic tick-borne illnesses is increasing and represents a growing public health concern. There are speculations that this is likely due to a complex combination of changes in the ecology, climate, increased human activity in affected areas, and improved detection of pathogens including higher awareness of primary health care providers $(2,3)$.

During the last 30 years, TBE has become an increasing health problem in Europe and other parts of the world. TBE is endemic in areas extending from Central and Eastern Europe to Siberia and parts of Asia. TBEV occurs in Central Europe, the Baltic and Scandinavian countries, and the Russian Federation (2).

To understand the above mentioned changes, it is necessary to know where TBEV occurs, where the vectors are a potential hazard, and where, as a consequence, autochthonous TBE cases have been registered.

The primary objective of this study is to provide an overview of local incidence of TBE in Slovakia during the period from 1992 to 2012. The authors also analyzed cases of TBE according to age, clinical forms of the disease and possible modes of transmission of infection. In the study, the authors discuss possible causes of the increase of TBE in Slovakia.

\section{MATERIALS AND METHODS}

The data were obtained from the Annual Reports for the years 2007-2012 available on the websites of the Public Health Authority (4) and from the Epidemiological Information System EPIS (5). Children population data about vaccination coverage are reported by primary health care paediatricians to the local Public Health Authority.

The comprehensive tables and graphs were created with the purpose to show changes in TBE frequency and incidence to demonstrate and confirm the most common mode of transmission of TBE disease, and also to confirm the most prevalent clinical forms of TBE and age differences in the occurrence of the disease between 2007 and 2012. Graphic complete outputs were created using summary contingency tables and graphs in the EXCEL programme.

\section{RESULTS}

A total number of $107(1.98 / 100,000)$ human TBE cases in Slovakia was confirmed and reported in 2012 (as diagnosis A84 Tick-borne viral encephalitis in the IDC-10 classification).

The European subtype (A84.1 Central-European tick-borne encephalitis) was reported in 102 cases $(1.89 / 100,000)$, which is a decrease of $6 \%$ compared to 2011 and an increase of $24 \%$ compared to the 5-year average values. Five cases $(0.09 / 100,000)$ were reported as Unspecified tick-borne viral encephalitis (A84.9). 
The incidence was reported separately for each region, with the highest values in Žilina (4.64) and Trenčín (4.54). The diseases occurred in each age group except for the infants. The highest agespecific morbidity was noted in the groups of 45-54 (2.40) and 55-64 years old subjects (2.39). The following clinical forms of diseases were reported: meningeal in 78 cases, febrile in 24 cases, neurological (disorders of balance, concentration, memory and speech, mood swings, fatigue, headache) in 4 cases, and intestinal in 1 case. The epidemiological history of patients reported: tick bite in 58 cases, indeterminate cause in 22 cases, ingestion in 18 cases, inoculation in 5 cases, and bites by other unknown insect in 3 cases. The majority of diseases occurred in June $(n=34)$ and October $(n=20)$. No case was reported in the previously vaccinated subjects. There was only one case of infection imported from the Czech Republic. Two outbreaks of TBE reported in 2012 were associated with raw goat milk and dairy products consumption. In the first case, it was an outbreak involving 12 infected people in Lučenec city district. In the second case, it was a family outbreak in Žilina city district, where 3 persons out of 4 family members were infected. TBE was serologically confirmed using the ELISA test with positive expression of $\operatorname{IgM}$ antibodies.

In 2011, a total number of 108 cases was reported. Only one death of a 45 -year-old man was confirmed. He lived in Levoča district and performed community service work. The epidemiological history was obtained from relatives since he was comatose. There was no history of vaccination and there was no evidence of acquiring a tick bite. The consumption of sheep and goat milk was ruled out by relatives. The autopsy showed a bilateral lobular pneumonia associated with tick-borne encephalitis as the primary disease.

Furthermore, a total number of 91 cases $(1.68 / 100,000)$ was reported in 2010, compared to 76 cases $(1.40 / 100,000)$ in 2009 , 79 cases $(1.46 / 100,000)$ in 2008 , and 57 cases $(1.06 / 100,000)$ in 2007. Table 1 and Figure 1 summarize the total number of human TBE cases and the incidence from 1992 to 2012. In the study period, morbidity was highest in 2011 with 108 reported cases and lowest in 1992 with 16 cases. The surveillance of TBE in the other years showed the following results: $1993 n=51,1994$ $\mathrm{n}=60,1995 \mathrm{n}=89,1996 \mathrm{n}=101,1997 \mathrm{n}=76,1998 \mathrm{n}=54,1999$

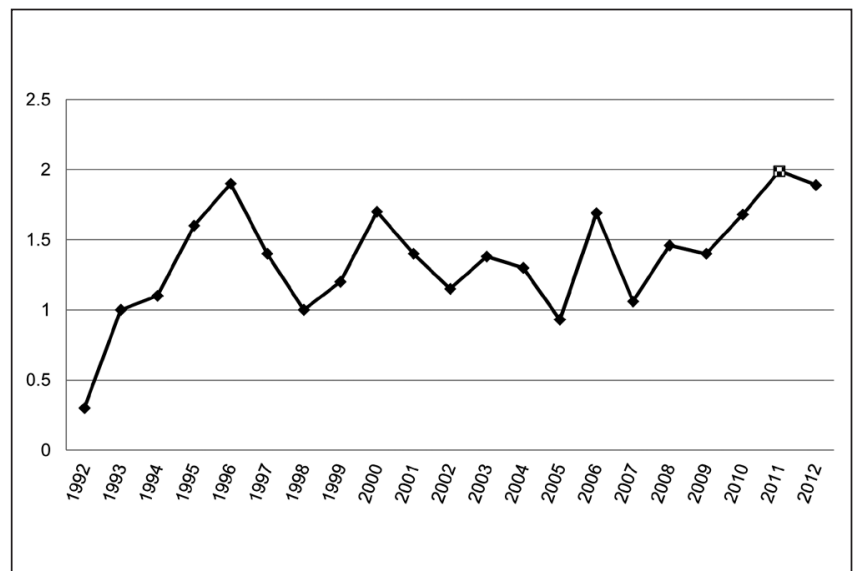

Fig. 1. Time trends in the incidence of TBE in Slovakia from 1992 to $2012(4,5)$.

$\mathrm{n}=63,2000 \mathrm{n}=92,2001 \mathrm{n}=75,2002 \mathrm{n}=62,2003 \mathrm{n}=74,2004$ $\mathrm{n}=70,2005 \mathrm{n}=50,2006 \mathrm{n}=91(4,5)$.

Tables 2-4 and Figures 2-4 show TBE cases according to age, clinical form and the mode of transmission for the period 2007-2011 (for the year 2012, no accurate data were available - age, clinical form of the disease or the supposed mode of TBE infection transmission). The five-year reference period shows the highest incidence of TBE in the age group of 55-64 years $(n=83)$. The most common mode of transmission was tick bite $(n=241)$ and the most frequent was the meningeal form of disease $(\mathrm{n}=302)(4,5)$.

\section{DISCUSSION}

The apparent increase in incidence of TBE in Central and Eastern Europe, especially since 1990, has been attributed to global warming or various socioeconomic factors. It has been shown that the climate change in Europe during the past decades has influenced the distribution of I. ricinus tick, which is the main TBEV vector in several European countries.

Table 1. The number of human TBE cases and incidence in Slovakia from 1992 to $2012(4,5)$

\begin{tabular}{|c|c|c|c|c|c|c|c|c|}
\hline \multirow{2}{*}{1992} & $n$ & 16 & \multirow{2}{*}{1999} & $n$ & 63 & \multirow{2}{*}{2006} & $n$ & 91 \\
\hline & inc. & 0.30 & & inc. & 1.20 & & inc. & 1.69 \\
\hline \multirow{2}{*}{1993} & $n$ & 51 & \multirow{2}{*}{2000} & $n$ & 92 & \multirow{2}{*}{2007} & $n$ & 57 \\
\hline & inc. & 1.00 & & inc. & 1.70 & & inc. & 1.06 \\
\hline \multirow{2}{*}{1994} & $n$ & 60 & \multirow{2}{*}{2001} & $n$ & 75 & \multirow{2}{*}{2008} & $n$ & 79 \\
\hline & inc. & 1.10 & & inc. & 1.40 & & inc. & 1.46 \\
\hline \multirow{2}{*}{1995} & $n$ & 89 & \multirow{2}{*}{2002} & $n$ & 62 & \multirow{2}{*}{2009} & $\mathrm{n}$ & 76 \\
\hline & inc. & 1.60 & & inc. & 1.15 & & inc. & 1.40 \\
\hline \multirow{2}{*}{1996} & $n$ & 101 & \multirow{2}{*}{2003} & $n$ & 74 & \multirow{2}{*}{2010} & $n$ & 91 \\
\hline & inc. & 1.90 & & inc. & 1.38 & & inc. & 1.68 \\
\hline \multirow{2}{*}{1997} & $n$ & 76 & \multirow{2}{*}{2004} & $n$ & 70 & \multirow{2}{*}{2011} & $n$ & 108 \\
\hline & inc. & 1.40 & & inc. & 1.30 & & inc. & 1.99 \\
\hline \multirow{2}{*}{1998} & $n$ & 54 & \multirow{2}{*}{2005} & $n$ & 50 & \multirow{2}{*}{2012} & $n$ & 102 \\
\hline & inc. & 1.00 & & inc. & 0.93 & & inc. & 1.89 \\
\hline
\end{tabular}


Table 2. The occurrence of TBE according to age from 2007 to $2011(4,5)$

\begin{tabular}{|c|c|c|c|c|c|c|}
\hline Age & 2007 & 2008 & 2009 & 2010 & 2011 & Total \\
\hline $1-4$ & 1 & - & 1 & 0 & 2 & 4 \\
\hline $5-9$ & 1 & 4 & 2 & 2 & 3 & 12 \\
\hline $10-14$ & 4 & 1 & 2 & 2 & 2 & 11 \\
\hline $15-19$ & 3 & 5 & 5 & 0 & 10 & 23 \\
\hline $20-24$ & 2 & 5 & 6 & 8 & 11 & 32 \\
\hline $25-34$ & 10 & 11 & 11 & 10 & 11 & 53 \\
\hline $35-44$ & 9 & 17 & 13 & 15 & 16 & 70 \\
\hline $45-54$ & 12 & 18 & 17 & 15 & 18 & 80 \\
\hline $55-64$ & 9 & 9 & 11 & 28 & 26 & 83 \\
\hline $65+$ & 6 & 9 & 8 & 11 & 9 & 43 \\
\hline Total & 57 & 79 & 76 & 91 & 108 & 411 \\
\hline
\end{tabular}

Table 3. The number of clinical forms of TBE from 2007 to $2011(4,5)$

\begin{tabular}{|l|c|c|c|c|c|c|}
\hline Clinical forms & $\mathbf{2 0 0 7}$ & $\mathbf{2 0 0 8}$ & $\mathbf{2 0 0 9}$ & $\mathbf{2 0 1 0}$ & $\mathbf{2 0 1 1}$ & Total \\
\hline Meningeal & 37 & 63 & 56 & 70 & 76 & 302 \\
\hline Febrile & 11 & 11 & 19 & 16 & 22 & 79 \\
\hline Neurological & 7 & 4 & 1 & 4 & 9 & 25 \\
\hline Other & 2 & 1 & - & 1 & 1 & 5 \\
\hline Total & 57 & 79 & 76 & 91 & 108 & 411 \\
\hline
\end{tabular}

Table 4. The occurrence of TBE according to anamnesis from 2007 to $2011(4,5)$

\begin{tabular}{|l|c|c|c|c|c|c|}
\hline Mode of transmission & $\mathbf{2 0 0 7}$ & $\mathbf{2 0 0 8}$ & $\mathbf{2 0 0 9}$ & $\mathbf{2 0 1 0}$ & $\mathbf{2 0 1 1}$ & Total \\
\hline Tick bite & 34 & 38 & 48 & 49 & 72 & 241 \\
\hline Ingestion & 4 & 8 & 5 & 6 & 4 & 27 \\
\hline Tick bite + ingestion & 1 & - & 1 & - & - & 2 \\
\hline Insect bite & - & 3 & 1 & 3 & 3 & 11 \\
\hline Inoculation & - & - & - & 3 & 1 & 4 \\
\hline Other & 3 & 12 & 4 & 1 & 29 & 105 \\
\hline Unknown & 15 & 18 & 17 & 91 & 108 & 411 \\
\hline Total & 57 & 79 & 76 & & & 26 \\
\hline
\end{tabular}

Between 1961 and 1979, the mean altitude of tick survival in the Slovak Republic varied between $180 \mathrm{~m}$ and $340 \mathrm{~m}$ above sea level. However, during the following period of 1980-2004, the highest location of vector's occurrence observed for several years in a row was $832 \mathrm{~m} \mathrm{(6).}$

In the Czech Republic, recent reports suggest that the altitude distribution limits of both I. ricinus and TBEV have changed from $700 \mathrm{~m}$ to about $1,200 \mathrm{~m}$ above sea level (7).

It has been reported that ticks (I. ricinus) and TBEV spread north in Sweden, Norway, and Finland. The geographical distribution range of $I$. ricinus used to be located below $61^{\circ} \mathrm{N}$, but ticks are now established along the whole Baltic Sea coastline (up to $66^{\circ} \mathrm{N}$ ) (3).

Factors that help tick populations thrive are non-extreme temperatures, high humidity and the presence of snow cover during the winter, which acts as insulation. The last decades' increased mean annual temperature may have provided more favourable conditions for ticks. Early springs with rapidly increasing temperatures as well as not too hot or dry summers may have been important positive factors for tick survival and reproduction success $(8,9)$.

Apart from changing climate conditions, social, political, ecological, economic, and demographic factors appear to play a role in aiding the spread of tick-borne diseases. These include changes in land usage (such as increased forestation or newly created gardens) and the growing popularity of outdoor pursuits such as hill-walking and fishing. In particular, socioeconomic conditions have an impact on the incidence of TBE, e.g., poor people (unemployed or dislodged due to political upheaval) are less likely to be vaccinated against TBEV and tend to look for food such as wild fruit and mushrooms in the forest, thus increasing the risk of a tick bite (1).

According to the results presented here, the highest TBE incidence was in the age group of 55-64 years old. The shift of the 


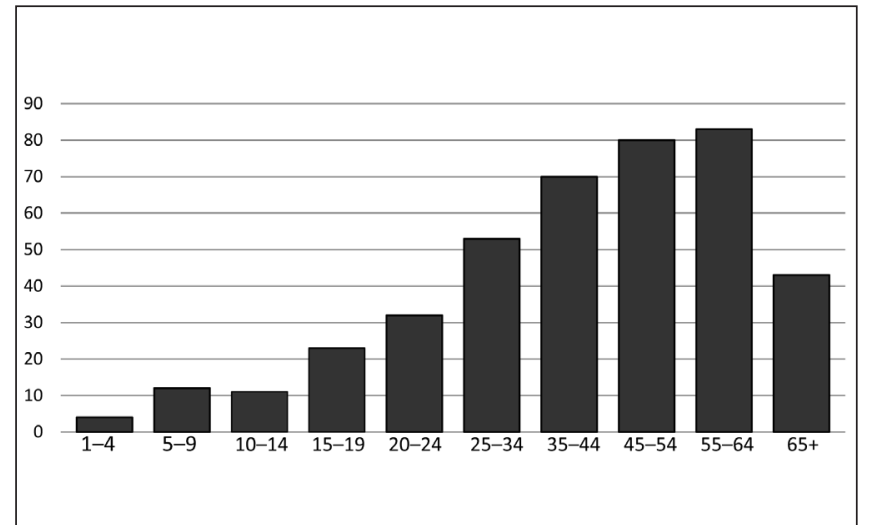

Fig. 2. The occurrence of TBE according to age from 2007 to 2011 (4, 5).

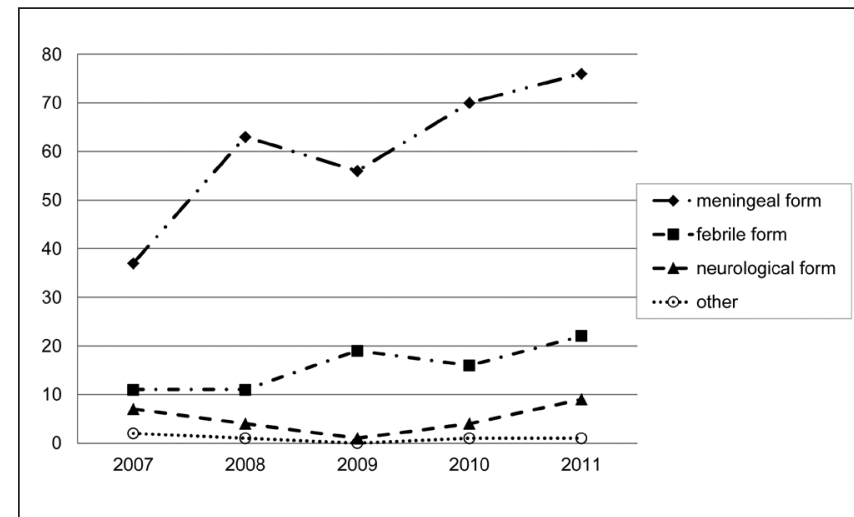

Fig. 3. Time trends in the number of clinical forms of TBE from 2007 to $2011(4,5)$.

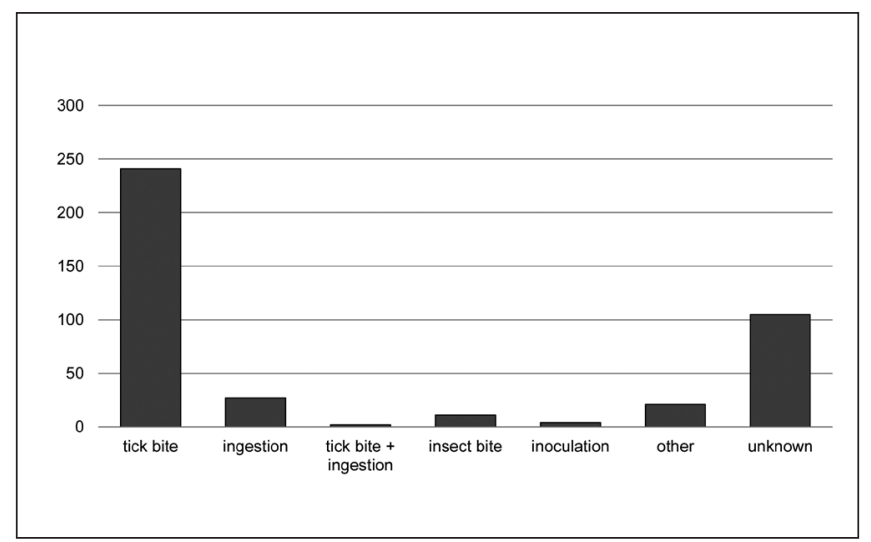

Fig. 4. Total occurrence of TBE according to anamnesis from 2007 to $2011(4,5)$. disease to older age group is caused primarily by the change of lifestyle of older people - spending more time outdoors during their recreational activities (10).

According to anamnestic data, the disease occurred most often after a tick bite and after consuming unpasteurized milk from infected animals. Large domestic animals such as goats, sheep and cattle are potential hosts of I. ricinus. In terms of foodborne disease, the highest risk is associated mainly with sheep and goats (2), but there also have been cases related to drinking of cow's milk $(11,12)$.

Active vaccination is the most effective method of TBE prevention. Modern vaccines are safe and their effectiveness ranges from $95 \%$ to $99 \%(12,13)$.

In Slovakia, a total number of 8,491 children under 15 years of age were vaccinated in 2012, according to data from the Public Health Authority of the Slovak Republic. Single dose of vaccine was administered in 1,276 cases, two doses in 2,137 cases, three doses in 2,715 and revaccination in 2,363 cases. The reported results show (Table 5, Figure 5) a decrease of more than $50 \%$ in vaccination compared to the year $2009(n=17,093)(4)$.

TBE immunization data of adults are not available, but the estimated vaccination coverage in Slovakia is $1 \%(1.3 / 100,000)$. The outputs on the percentage of TBE vaccination coverage of the Slovak adult population were obtained annually from the distributors and pharmacies or from health insurance companies. The highest vaccination coverage $(88 \%)$ is in Austria $(14,15)$.

The decrease of TBE vaccination can be partially associated with the general upsurge of activities against vaccination. This may result in refusals of the vaccination by parents. Another aspect of the immunization process of TBE in Slovakia is the Decree No. $585 / 2008$ Coll. of the Ministry of Health of the Slovak Republic,

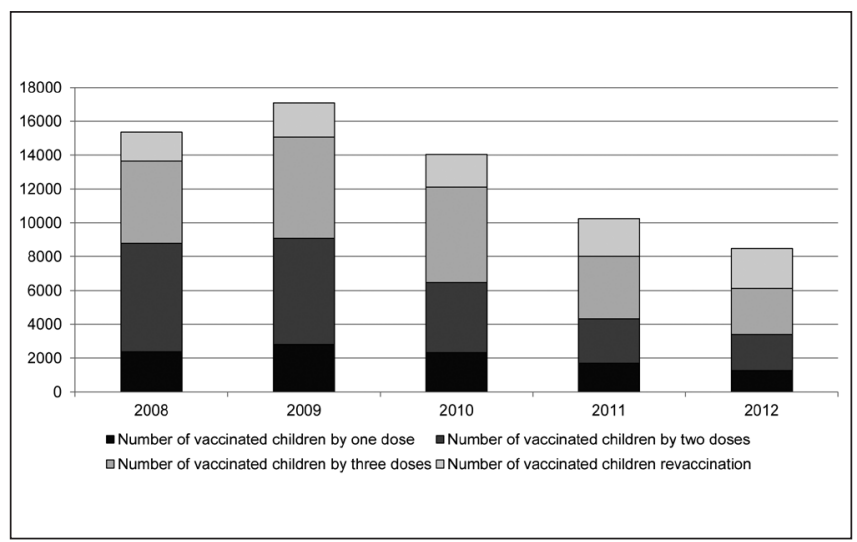

Fig. 5. Number of TBE vaccinated children under 15 years from 2008 to 2012 (4).

Table 5. Number of TBE vaccinated children under 15 years from 2008 to 2012 (4)

\begin{tabular}{|l|c|c|c|c|c|}
\hline \multirow{2}{*}{ Year } & \multicolumn{5}{|c|}{ Number of vaccinated children } \\
\cline { 2 - 6 } & total & one dose & two doses & three doses & revaccination \\
\hline 2008 & 15,364 & 2,387 & 6,401 & 4,855 & 1,728 \\
\hline 2009 & 17,093 & 2,804 & 6,277 & 5,986 & 2,026 \\
\hline 2010 & 14,025 & 2,330 & 4,133 & 5,654 & 1,916 \\
\hline 2011 & 10,242 & 1,695 & 2,628 & 3,679 & 2,240 \\
\hline 2012 & 8,491 & 1,276 & 2,137 & 2,715 & 2,363 \\
\hline
\end{tabular}


which defines details on prevention and control of communicable diseases. This regulation recommends the vaccination only for the occupationally exposed persons (i.e. forest workers, agricultural workers, borderline police officers, soldiers, army forces, selected laboratory workers, etc.) but does not make it compulsory for this groups of population (16).

The low interest in vaccination is probably caused by poor economic situation as well. The vaccine is not fully reimbursed by health insurance system. The insurance companies reimburse only $50 \%$ of the total price of vaccine (17-18).

\section{CONCLUSION}

TBE with its severe symptoms, possible late effects of the disease and risk for chronic disability is of growing concern to public health authorities in Europe. High incidence and new foci have appeared in the last decades. Molecular methods, particularly PCR (polymerase chain reaction) have also brought huge changes in tick-borne disease research and detection. The incidence of tickborne encephalitis in Slovakia in the period 2007-2012 showed an increase or fluctuation with the highest incidence point in 2011. New directions and standards approved by the European Commission (19) avoid previous problems with standard case definition and varying diagnostic procedures. These recommendations also prevent differences in the intensity and quality of national surveillance of TBE cases. Newly adopted directives exclude biases in the system of notification and reporting schemes and unify registry data for TBE disease in EU countries.

\section{Acknowledgement}

This work was supported by the Grant VEGA No. 1/0198/13 of the Ministry of Education, Science, Research and Sport of the Slovak Republic.

\section{REFERENCES}

1. Mansfield KL, Johnson N, Phipps LP, Stephenson JR, Fooks AR, Solomon T. Tick-borne encephalitis virus - a review of an emerging zoonosis. J Gen Virol. 2009 Aug;90(Pt 8):1781-94.

2. Süss J. Tick-borne encephalitis 2010: epidemiology, risk areas, and virus strains in Europe and Asia-an overview. Ticks Tick Borne Dis. 2011 Mar;2(1):2-15.

3. Gray JS, Dautel H, Estrada-Peña A, Kahl O, Lindgren E. Effects of climate change on ticks and tick-borne diseases in Europe. Interdiscip Perspect Infect Dis. 2009;2009:593232. doi: 10.1155/2009/593232.

4. Public Health Authority of the Slovak Republic. Annual report [Internet]. Bratislava: Public Health Authority of the Slovak Republic; (C)
2009 [cited 2014 Sep 4]. Available from: http://www.uvzsr.sk/index. php?option $=$ com_content $\&$ view $=$ category $\& i d=25$ :vyrocna-sprava\&lay out=blog\&Itemid=34\&layout=default). (In Slovak.)

5. Epidemiological information system. Annual reports [Internet]. Bratislava: Public Health Authority of the Slovak Republic; (C) 2006 [cited 2014 Sep 4]. Available from: http://www.epis.sk/InformacnaCast/Publikacie/ VyrocneSpravy.aspx. (In Slovak.)

6. Lukan M, Bullova E, Petko B. Climate warming and tick-borne encephalitis, Slovakia. Emerg Infect Dis. 2010 Mar;16(3):524-6.

7. Danielová V, Rudenko N, Daniel M, Holubová J, Materna J, Golovchenko $\mathrm{M}$, et al. Extension of Ixodes ricinus ticks and agents of tick-borne diseases to mountain areas in the Czech Republic. Int J Med Microbiol. 2006 May;296 Suppl 40:48-53.

8. Lundkvist A, Wallensten A, Vene S, Hjertqvist M. Tick-borne encephalitis increasing in Sweden, 2011. Euro Surveill. 2011 Sep 29;16(39). pii: 19981.

9. Lindhe KE, Meldgaard DS, Jensen PM, Houser GA, Berendt M. Prevalence of tick-borne encephalitis virus antibodies in dogs from Denmark. Acta Vet Scand. 2009 Dec 29;51:56. doi: 10.1186/1751-0147-51-56.

10. Kříž B, Beneš Č. The incidence of tick-borne encephalitis in the Czech Republic in 2010. Zprávy CEM (NIPH, Prague). 2011;20(5):178-82. (In Czech.)

11. Caini S, Szomor K, Ferenczi E, Szekelyne GA, Csohan A, Krisztalovics $\mathrm{K}$, et al. Tick-borne encephalitis transmitted by unpasteurised cow milk in western Hungary, September to October 2011. Euro Surveill. 2012 Mar 22;17(12). pii: 20128.

12. Dumpis U, Crook D, Oksi J. Tick-borne encephalitis. Clin Infect Dis. 1999 Apr;28(4):882-90.

13. Heinz FX, Holzmann H, Essl A, Kundi M. Field effectiveness of vaccination against tick-borne encephalitis. Vaccine. 2007 Oct 23;25(43):755967.

14. Kunz C. TBE vaccination and the Austrian experience. Vaccine. 2003 Apr 1;21 Suppl 1:S50-5.

15. Donoso Mantke O, Escadafal C, Niedrig M, Pfeffer M, Working Group For Tick-Borne Encephalitis Virus C. Tick-borne encephalitis in Europe, 2007 to 2009. Euro Surveill. 2011 Sep 29;16(39). pii: 19976.

16. Decree No. 585/2008 Coll. of the Ministry of Health of the Slovak Republic, which defines details on prevention and control of communicable diseases. Zbierka zákonov SR. 2008 Dec 10;Pt 202:5024-41. (In Slovak.)

17. Vaccination against tick-borne encephalitis [Internet]. Nitra: Dovera; 2014 [cited 2014 Sep 4]. Available from: http://www.dovera.sk/poistenec/ tema-nadstandard-od-dovery/a53/ockovanie-proti-kliestovej-encefalitide. (In Slovak.)

18. Tick-borne encephalitis. Reimbursement of vaccination by insurance companies [Internet]. Baxter; 2014 [cited 2014 Sep 4]. Available from: http://www.kliest.sk/verejnost/70/uhrada-ockovania-poistovnami. (In Slovak.)

19. Commission implementing decision of 8.8.2012 amending Decision 2002/253/EC laying down case definitions for reporting communicable diseases to the Community network under Decision No 2119/98/EC of the European Parliament and of the Council [Internet]. Brussels: European Commission; 2012 [cited 2014 Sep 4]. Available from: http://www.fhi. no/dokumenter/23cf9ecb6a.pdf\#page=10\&zoom =auto,-274,229.

Received June 3, 2013 Accepted in revised form September 4, 2014 